\title{
articles
}

\section{Continuity of care of outpatients with schizophrenia in Pretoria}

\author{
A M E Kotzè, DPhil (Social Work) \\ Manager, YANA Group Homes for Schizophrenic \\ Patients, Pretoria \\ W F van Delft, DPhil (Social Work), MA (Clin Psych) \\ Department of Social Work, United Arab Emirates \\ University, Al Ain, United Arab Emirates
}

J L Roos, MB ChB, MMed (Psych), MD, FCPsych Department of Psychiatry, Weskoppies Hospital and University of Pretoria

Objective. To study the needs of outpatients suffering from schizophrenia and their primary caregivers.

Methods. A qualitative descriptive design was selected to study the needs of a non-probability purposive sample of 50 outpatients with schizophrenia and their primary caregivers. Data were collected on their compliance-related needs as well as psychosocial and aftercare treatment needs.

Results. Compliance needs: Eighty-three per cent of the participants supported their medication treatment and aftercare, but needed more information on the illness than they had received or had managed to gather.

Psychosocial needs: Participants had difficulty in accepting the illness and in understanding its consequences for their everyday functioning. Ninety-seven per cent of patients were aware that their illness had affected the health of their primary caregiver. The majority of participants had lost friendships since the diagnosis of schizophrenia. Eighty-eight of the primary caregivers supported the patient financially, despite the fact that many were over 60 years of age.

Aftercare treatment needs: A strong need was expressed for services such as day-care centres, workshops, and psychoeducational and social work services.

Conclusions. As South African health policy is moving towards de-institutionalisation and treating mental health as part of primary care, support must be improved for sufferers of schizophrenia and their primary caregivers. Many people are prepared to face up to the challenge of caring for a mentally ill family member, yet are faced with significant needs that should be addressed.
In keeping with international trends, South African health policy promotes de-institutionalisation and treating mental health as an integral part of primary health care. Because hospital stay is made as short as possible, more people entering the primary health care system. ${ }^{2}$ When the necessary budgetary provisions are not made, the result is a lack of community resources that are essential for continuity of care for the mentally ill. ${ }^{3}$

In addition, social workers and other mental health practitioners working in the community often find that outpatients with schizophrenia struggle to function effectively in the family unit and in the community. They find it difficult to adjust to their environment, and some may be disruptive and even suffer a dismal quality of life.

To be effective, continuity of care, service planning and intervention should focus on the needs of both outpatients and their primary caregivers, because the primary caregivers of these patients are further burdened by experiencing existential crises when confronted with this illness and the demands their role as carer make on them.

We have experienced numerous enquiries about supportive and rehabilitation services from outpatients suffering from schizophrenia and their primary caregivers. We therefore undertook this study with the aim of gaining an understanding of the needs of these patients and the people who look after them.

\section{Method}

A qualitative research design was chosen for this study for the following reasons: (i) a qualitative research design is concerned with understanding rather than explanation, and naturalistic observation rather than controlled measurement; ${ }^{4}$ (ii) to gain this understanding, it is important to engage in an empathetic process of communication in which participants can express their fears, needs, feelings and experiences of living with schizophrenia nevertheless, we also present numerical data, for these are not excluded by a qualitative approach; (iii) interview guides assisted in the expression of the participants' subjective experiences regarding their compliance, psychosocial and aftercare treatment needs; and (iv) interviewees were made aware that they were not obliged to answer questions they preferred not to. This 
arrangement, as well as the consent form, made them feel more at ease about participating. ${ }^{5}$

\section{Ethics approval}

Ethics approval for the study was obtained from the Research Ethics Committee of the Faculty of Health Sciences, University of Pretoria, and permission for conducting the study was obtained from the CEO of Weskoppies Psychiatric Hospital, Pretoria.

\section{Participants}

The first group of participants were 50 outpatients suffering from schizophrenia. The second group consisted of the 50 primary caregivers of these patients. A non-probability sampling method (convenience sampling) was used.' Patients and their primary caregivers were recruited from the outpatient facility at Weskoppies Psychiatric Hospital in Pretoria, as well as from outpatient groups and primary caregivers who contacted the researcher for support.

Patients involved in an aftercare programme in the community, living with a primary caregiver, and who had been hospitalised at least once were included. Primary caregivers had to be the parent, spouse or child of the patient.

\section{Study procedures}

Two interview guides were constructed with the same categories and questions - one for patients and one for the primary caregivers, allowing for comparisons between the patients and their caregivers. The interview guides were constructed using the relevant literature on the topic, as well as information gathered from psycho-educational groups conducted by the researchers over time. They consisted of a checklist of topics addressing the categories of treatment compliance needs, as well as psychosocial and aftercare treatment needs. Each category consisted of nine questions. ${ }^{6}$ To increase the trustworthiness of observations and conclusions drawn from them, the interview guides had first been piloted with three patients and two caregivers who were not included in the study groups. It was not within the scope of the study to assess participants' knowledge of schizophrenia or their insight into the illness with standard quantified instruments.

\section{Results}

\section{Socio-demographics}

\section{Gender, age and marital status}

As can be expected from the prevalence of schizophrenia in the general population, there were more male $168 \%$ ) than female (32\%) participants. Forty-six per cent of the participants in all three population groups fell into the age category 30 - 39 years, not one female being under the age of 30 years; $59 \%$ of the participants (patients) had never been married.

Fifty-eight per cent of the primary caregivers fell into the age group 60 years and over. Forty-eight per cent of the primary caregivers were married at the time of the research.

\section{Educational level and source of income}

Seventy-five per cent of the patients had completed high school education, with more females (66\%) having done so. The major source of income of all patients was a disability grant. Over $70 \%$ of caregivers provided additional financial support for the patients. Forty-four per cent of the primary caregivers worked full time, 22\% received an old-age pension, and 22\% received a pension from previous work.

\section{Living arrangements of discharged patients}

Sixty-six per cent of the patients lived with their parents.

\section{Re-admissions}

Fifty-one per cent of the patients had been admitted more than four times during the course of the illness. Reported non-compliance with medication and substance abuse were given as possible reasons for participants' relapses.

\section{Compliance needs of patients}

\section{Knowledge of the illness}

The interview guide was used to assess patient knowledge about what schizophrenia was. Questions included the following: 'Do you know what schizophrenia is?', 'Did professionals explain the illness to you?', and 'Do you know what the positive and negative symptoms are?' Similar questions were directed to the primary caregivers.

Eighty-six per cent of the patients could not demonstrate knowledge about what schizophrenia was. Responses included: 'No, I don't know, they did not explain, they said there is something wrong in my head.' Eighty-eight per cent of the patients and 92\% of their primary caregivers reported that professionals had not explained the illness to them. Ninety-six per cent of the patients and 100\% of the primary caregivers did not know what the positive and negative symptoms were. Primary caregivers' responses included: 'I don't know the illness, I want to know what is going on with my child, I am lost in the darkness.' 


\section{Medication treatment, medical aftercare and discontinuation of medication}

At the time of the interview $87 \%$ of the respondents supported medication treatment, and all the patients attended medical aftercare. Fifty-two per cent of the patients reported that they had discontinued medication during the course of their illness. Fifty-six per cent of the primary caregivers reported that their child/family member (patient) had discontinued medication. This boils down to only a $4 \%$ points difference between the groups.

\section{Psychosocial needs}

\section{Feelings of being understood, loss of friends, decision making and health affected}

Fifty-two per cent of the patients reported that they felt that their primary caregivers understood their behaviour since they had been diagnosed. Primary caregivers were asked directly whether they understood the patient's behaviour since the patient had been diagnosed; $60 \%$ responded that they did understand the behaviour of their child or family member since the onset of illness. Seventy-four per cent of the patients reported that they had lost friends, and $48 \%$ of the primary caregivers had lost friends. Eighty-eight per cent of the patients reported that their primary caregivers made decisions for them, and $82 \%$ of the primary caregivers reported that they had to make decisions for their family members. Ninety-two per cent of patient participants reported that their illness had affected the health of their primary caregivers. This was an accurate perception according to the primary caregivers of these patients. Ninety-two per cent of the primary caregivers of these patients reported that their child's/ family member's illness did indeed affect their personal health.

\section{Aftercare treatment needs}

Eighty-seven per cent of the patients and $97 \%$ of the primary caregivers said that they supported medication treatment and medical aftercare. Sixty-four per cent of the patient group expressed the need to consult with a social worker, and 70\% of the primary caregivers expressed the same need. Reported needs regarding day-care centres and workshops were higher among the primary caregivers than the patients. Both groups of participants expressed a strong need for support groups and psycho-educational groups. Sixty-four per cent of the patient group expressed a need for support groups, and 84\% expressed a need to learn more about the illness. Ninety-four per cent of the primary caregivers needed support from other families and 98\% reported a need to learn more about the illness. Lack of information about the illness was commonly reported, and a high proportion of both groups of participants expressed a need for information and support.

\section{Discussion}

Several similarities in compliance needs were found between the two groups of participants. One similarity is the lack of knowledge about the illness among participants, apart from what they had learned about it in their personal observations/experience of its symptoms. This might have been because they did not remember what they had been told by mental health practitioners; they may also have been too ill at the time to properly assimilate what they were told. However, it appeared to the researchers that the majority of participants in both groups had not been adequately informed about the illness.

Either way, the reported need for information in both groups of participants corresponds with the expressed need for psychoeducational groups to learn more about the illness. The fact that most of the participants had been outpatients for longer than 5 years and were still in need of information suggests that this need had not been addressed adequately for several years.

Conflicting points of view were expressed in that patients felt they were being treated like children, especially concerning financial matters, whereas caregivers felt it important, if not imperative, to make decisions for their child or family member.

The need for psychosocial and aftercare treatment programmes, support and psycho-educational groups for both groups of participants was striking. Participants expressed the need to talk about their illness and to learn more about the illness, as well as about its consequences with regard to their functioning. Patients had the impression that their illness had contributed to ill health of their caregivers, which caregivers confirmed as being accurate.

Notwithstanding these differences in the experiences of the patients and their caregivers, the findings made it clear that they needed support in managing their lives in both the family and the community settings.

The results of this research indicate that many people are prepared to accept the challenge of caring for a mentally ill family member. Yet they are faced with significant needs that should be addressed. The primary caregiver is as vulnerable as the patient, although not for the same reasons. It is therefore a logical deduction that unless caregivers are regarded as crucial role players in the continuity of care of outpatients with schizophrenia, the entire endeavour of aftercare will be ill-served. 


\section{Conclusions}

De-institutionalisation in South Africa should not only be a matter of reducing the number of hospital beds. It also requires the development of a comprehensive mental health care system that can provide continuity of care. Despite budgetary constraints, the urgent needs of mentally ill people at grassroots level should be brought to the attention of the Mental Health Directorate. The focus should not only be on the management of schizophrenia, for example, but also on managing its consequences for the patient, the caregiver and the community. The policy of de-institutionalisation is based on the concern for inpatient human rights, but has the undesirable consequence of psychotic people living in poverty and severe neglect when provision is not made for proper care and treatment in the community.

A system to link social work services in the psychiatric hospital with community-based social work services should be developed and implemented. Where possible, social workers in the community should be informed when patients with schizophrenia are about to be discharged from hospital. In the provision of continuity of care, the linkage of hospital-based care and community-based care is critical, ${ }^{8}$ which in turn underscores the need for the Department of
Social Development to reduce the shortage of social workers. If health care is to be successfully delivered at primary care level, social workers should be available to co-implement the hitherto neglected aspect of the Mental Health Care Act (Act 17 of 20021, ${ }^{9}$ which compels authorities to provide continuity of care that would address the needs of patients and caregivers.

The authors thank the patients and caregivers for their willingness to participate in this study.

\section{References}

1. Spaniol LR, Zipple AM, Lockwood D. The role of the family in psychiatric rehabilitation. Schizophr Bull 1992;18(3):341-347.

2. Swartz L, MacGregor H. Integrating services, marginalizing patients: Psychiatric patients and primary health care in South Africa. Transcult Psychiatry 2002;39(2): 155-172.

3. Emsley R. Focus on psychiatry in South Africa. Br J Psychiatry 200 1; 178:382-386.

4. De Vos AS, Strydom H, Fouche CB, Delport CSL. Research at Grassroots for the Social Science and Human Professions. 2nd ed. Pretoria: Van Schaik, 2002

5. Stiles WB. Quality control in qualitative research. Clin Psychol Rev 1993; 13:595

6. Dooley D. Social Research Methods. 3rd ed. Englewood Cliffs, NJ: Prentice-Hall, 1995: 270.

7. Warner R. Recovery from Schizophrenia: Psychiatry and Political Economy. London: لل Press, 1994: 27.

8. Systema S, Micciolo R, Tansella M. Continuity of care for patients with schizophrenia and related disorders: A comparative South-Verona and Groningen case-register study. Psychol Med 1997;27:1357.

9. New Mental Health Care Act (Act 17 of 2002). Government Gazette No. 27117 1-76. 